Bulletin of Pharmaceutical Sciences
Assiut University
Website: http://bpsa.journals.ekb.eg/
e-mail: bullpharm@aun.edu.eg

\title{
PROSPECTS FOR USING MITOGEN-ACTIVATED PROTEIN KINASES ERK1/2 AND p38 OF NERVE TISSUE PROGENITORS AS PHARMACOLOGICAL TARGETS FOR THE TREATMENT OF NEURODEGENERATION CAUSED BY ALCOHOL
}

\author{
Gleb N. Zyuz'kov ${ }^{*}$, Larisa A. Miroshnichenko, Elena V. Simanina and Tatyana Yu. Polyakova
}

Goldberg Research Institute of Pharmacology and Regenerative Medicine, Tomsk National Research Medical Center, Russian Academy of Sciences, Tomsk, Russia, 3 Lenin Prospect, Tomsk, 634028, Russia

\begin{abstract}
We studied the possibility of using ERK1/2 inhibitor and p38 inhibitor to modulate the functions of nerve tissue precursor cells in ethanol-induced neurodegeneration. It has been found that in chronic alcoholization of mice both these pharmacological substances are able to increase proliferative activity of neural stem cells (NSC). In addition, the blockade of ERK1/2 initiates the progression of the cell cycle of the neuronal-committed progenitors (NCP, clonogenic PSA-NCAM + cells). This reduces the differentiation intensity of NSC and clonogenic PSA-NCAM + cells under the influence of the ERK1/2 inhibitor and such in NSC under the influence of p38 inhibitor. The fundamental difference between the functions of ERK1/2 and p38 in the regulation of the NSC and NCP cell cycle in optimal living conditions and in ethanol-induced neurodegeneration does not allow to draw unambiguous conclusions about the prospect of using these protein kinases as pharmacological targets of drugs for the therapy of alcoholic encephalopathy.
\end{abstract}

\section{INTRODUCTION}

The promising approach to solving the problems of regenerative medicine is a pharmacological strategy based on the principle of targeting individual parts of intracellular signal transduction in regeneration-competent cells $^{1 \& 2}$. The fundamental possibility of selective stimulation of the regeneration of various organs and tissues is determined by the peculiarity of intracellular signaling in histogenetically and functionally different progenitors ${ }^{3 \& 4}$ against the background of tissuespecific types, subtypes and isoforms of signal proteins (including products of alternative splicing $)^{1}$. In this regard, a detailed understanding of the individual role of signaling molecules in the regulation of the cell cycle of the parent elements is of paramount importance in the implementation of this direction and for the target-oriented search for candidates for such targeted agents with regenerative activity. Moreover, the relevance of creating fundamentally new drugs for the treatment of neurodegenerative diseases ${ }^{5 \& 6}$ makes it necessary to study the specifics of intracellular signaling in regeneratively competent cells of the nervous tissue.

The important role of mitogen-activated protein kinases (MAPK)-signaling pathways in determining the functional state of cellular elements is known. Earlier, we discovered a number of features of the participation of the "classical" - ERK1/2-mediated, and "alternative" - p38-dependent, MAP kinase signaling in the realization of the growth potential of some predecessors, including neural $\mathrm{SC}^{7 \& 8}$. At the same time, neurogenesis can be stimulated by activating the functions of both neural stem cells (NSC) and committed neuronal progenitors (neuronal-committed progenitors, $\mathrm{CNP})^{9 \& 10}$. Therefore, signaling 
molecules should be considered promising targets for pharmacological effects, at least not having the opposite importance in the regulation of cell division processes of NSC and CNP. Obviously, activity modifiers of proteins that play a different role in the cells of these populations in the vector are not capable of balanced neurogenesis. In addition, it is necessary to take into account the possible differences in the participation of individual parts of the signal transduction under the influence of a pathogenic factor from that with the optimal vital activity of cells ${ }^{1}$. Moreover, based on their alleged patterns of implementation of the developed concept, drug intervention should entail a transformation / "normalization" during the therapy of the intracellular signaling pattern in regeneratively competent cells formed de novo. In this regard, changes in the activity / expression of these signaling molecules (targets) under the influence of a pharmacological agent should not interfere with the functioning of intact NSC and CNP. The indicated criteria represent "threshold" / basic requirements for designating signaling molecules as promising targets for the treatment of neurodegenerative conditions of various origins.

One of the most common and incurable existing approaches neuropsychiatric diseases are irreversible alcohol-associated disorders of the central nervous system ${ }^{11 \& 12}$.

The aim of the work was to identify the features of the participation of ERK1/2 and p38 in realizing the growth potential of neural SCs and committed neuronal precursors in ethanolinduced neurodegeneration modeled in-vitro and in-vivo.

\section{MATERIALS AND METHODS}

\section{Chemicals and drugs}

Serum-free MACS ${ }^{\circledR}$ Neuro Medium; antiPSA-NCAM MicroBeads (all manufactured by Miltenyi Biotec, Germany); ERK1/2 inhibitor (PD98059) (Calbiochem, USA) and p38 inhibitor (SB203580) (Calbiochem, USA); hydroxyurea (Calbiochem, USA); plastic plates for cultural studies («Costar», USA).

\section{Animals and experimental design \\ All in-vivo experiments were carried out \\ in accordance with the U.K. Animals}

(Scientific Procedures) Act, 1986 and associated guidelines, EU Directive 2010/63/EU for animal experiments. The study was approved by the Institute local Ethics Committee. Experiments were carried out on C57B $1 / 6$ mice $(n=56)$ at the age of $2-2.5$ months, weighing 20-22 g. Animals of the $1 \mathrm{st}$ category (conventional linear mice) were obtained from Experimental Biological Models, Department of Goldberg Research, Institute of Pharmacology and Regenerative Medicine (Tomsk, Russia) (certificate available). Before the beginning of experiments (during 10 days) and over the study period, animals were contained in vivarium (air temperature $20-22^{\circ} \mathrm{C}$, humidity $50-60 \%$ ) in plastic cages (10-15 mice) on a normal diet (solid diet pellets obtained from Limited Liabilily Company «Assortiment Firm», Sergiev Posad sity, Russia), water ad libitum. In order to exclude seasonal fluctuations of studied parameters, all the experiments were performed in the autumn-winter period. The animals were removed from the experiment (sacrificed) using $\mathrm{CO}_{2}$ cameras.

Using the cultural methods, we studied the direct effect of the ERK1/2 inhibitor (PD98059) $(100 \mu \mathrm{M})$ and p38 inhibitor $(10$ $\mu \mathrm{M})$ on the realization of the growth potential of neural tissue precursor cells (NSC, CPN) in the conditions of modeling ethanol-induced neurodegeneration in-vitro and in-vivo.

In-vitro ethanol-induced neurodegeneration was obtained by adding ethanol to the culture medium at a concentration $(65 \mathrm{mM})$. In-vivo modeling of the pathological state was carried out by oral administration of a $30 \%$ solution of $\mathrm{C}_{2} \mathrm{H}_{5} \mathrm{OH}$ (through a probe daily at a dose of $3 \mathrm{~g} / \mathrm{kg} /$ day for 8 weeks $)^{13}$. In this case, instead of drinking water of free access, a 5\% solution of ethyl alcohol was used. Cellular material for the study was taken 10 days after the end of the introduction of ethanol in-vivo. The control group in the same mode was injected with distilled water in an equivalent volume (mice had free access to drinking water).

\section{Determination of the progenitors content}

Neural stem cells were studied during the cultivation of unfractionated cells of the subventricular zone (SVZ) of the cerebral hemispheres. To study committed neuronal 
precursors (CPN) from the cells of the SVZ of the brain using an immunomagnetic separator "MIniMACS Cell Separator" (Miltenyi Biotec, Germany), PSA-NCAM (CD56 +) cells were obtained by positive selection ${ }^{14}$ (using appropriate antibody kits according to the methodological manufacturer's instructions). The obtained unfractionated and PSA-NCAM + cells at a concentration of $10^{5} / \mathrm{ml}$ were incubated in MACS Neuro Medium (Miltenyi Biotec, Germany) for 5 days in a $\mathrm{CO}_{2}$ incubator at $37^{\circ} \mathrm{C}, 5 \% \mathrm{CO}_{2}$ and $100 \%$ air humidity. After incubation in both cases (during the cultivation of unfractionated cells and PSA-NCAM + cells), the content of clonogenic cells, their mitotic activity, and intensity of specialization were calculated. The number of NSC and CPN was determined by the yield in the respective cultures of colony forming units (CFU, colonies containing more than 100 cells). The proliferative activity of the progenitor cells was assessed by the method of cell suicide using hydroxyurea $(1 \mu \mathrm{M})$. The pool of CFU in the $\mathrm{S}$-phase of the cell cycle was determined according to the formula: $\mathrm{N}=[(\mathrm{a}-\mathrm{b}) / \mathrm{a}] \times 100 \%$, where $a$ is the average for the group the number of CFU from cells not treated with hydroxyurea; $b$ - the average for the group the number of CFU from cells treated with hydroxyurea. The intensity of the processes of specialization (differentiation / maturation) of progenitor elements was determined by calculating the ratio of the corresponding cluster-forming (CIFU, neurospheres of 30-100 cells) to CFU (differentiation index) ${ }^{3}$.

\section{Statistical analysis}

The results were analyzed with one-way ANOVA followed by Dunnett's test, Wilcoxon's test for dependent samples, and Mann-Whitney test for independent samples. The data are expressed as the arithmetic means. The significance level was $p<0.05^{15}$.

\section{RESULTS AND DISCUSSION}

\section{Effects of ethanol on the functioning of various types progenitors cells}

Ethanol addition into the culture medium was not accompanied by a change in the output of $\mathrm{CFU}$ and $\mathrm{ClFU}$ from both unfractionated cells of the subventricular zone of the brain (Figs. 1a, 1b) and PSA-NCAM + cells (Figs. 2a, 2b). However, there was a significant decrease in the division rate of multipotent (CFU-N_NSC) and committed predecessors $\left(\mathrm{CFU}-\mathrm{N} \_\mathrm{PSA}-\mathrm{NCAM}+\right)$ (Figs. 1c, 2c). Longterm alcoholization of experimental animals (ethanol administration in-vivo) led, in many respects, to similar changes in the functional characteristics of the studied progenitor cells. At the same time, a decrease in the output of CFU-N ${ }_{\text {PSA-NCAM }}+$ (Fig. 2a) and a suppression of the intensity of NSC specialization processes (Fig. 1d) were additionally recorded. The indicated phenomenology is fully consistent with the information we obtained earlier ${ }^{13}$ about the violation of the implementation, first of all, of the proliferative ability of progenitor cells of the nervous tissue, and about the more pronounced vulnerability of the pool of committed neuronal precursors when exposed to ethanol.

\section{Role of ERK1/2 and p38 in implementation functions various types progenitors}

The study of MAPK-dependent signal transmission pathways revealed in many respects a similar value of ERK $1 / 2$ and p38 in realizing the growth potential of progenitor cells. Inhibitors of both types of protein kinases reduced the yield of CFU-N_NSC and CFUN_PSA-NCAM + against the background of a decrease in the rate of their division (Figs. 1c, $2 c)$. In all cases, an increase in the rate of specialization of progenitor cells was also noted (Figs. 1d, 2d). However, the growth of the differentiation index was significantly more significant in the NSC. This circumstance was the result of a marked increase in the level of cluster formation in the culture of unfractionated cells of the SVZ during ERK1/2 and p38 blockade (Fig. 1b).

Thus, the fundamental differences in the role of the studied MAPKs in the regulation of the functions of multipotent progenitor elements and committed neuronal precursors were noted only among their most determinate in the development of population representatives (ClFU_NSC and CIFU-N_PSANCAM +). At the same time, one should not underestimate the potential significance of these phenomena in relation to ClFU from the standpoint of the possibility of controlling the regeneration of nerve tissue due to the pharmacological effect on their signaling. 


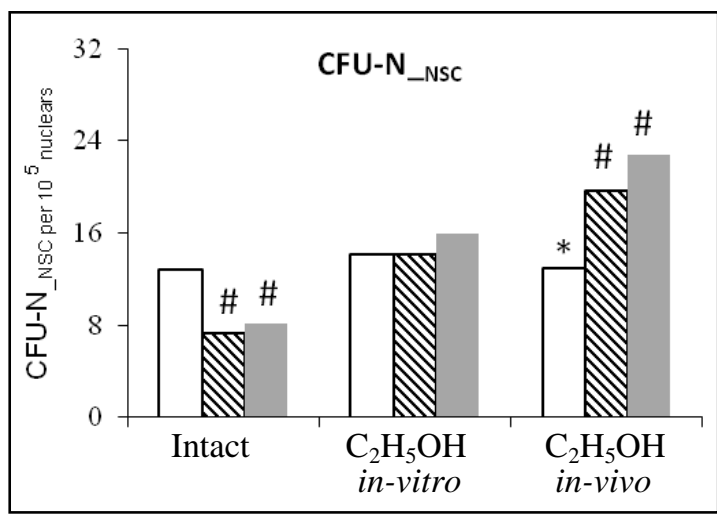

Fig. 1a: Number of CFU-N_NSC in the cell culture.

Here and in the figures 1-2: cell culture without alcohol (intact) and with alcohol $\left(\mathrm{C}_{2} \mathrm{H}_{5} \mathrm{OH}\right)$ without signaling molecule inhibitors (white bars) and when an ERK1/2 inhibitor (shaded bars) and an inhibitor and p38 (gray bars) are added to the medium.

* the significance of differences in indicators with intact was noted at $p<0.05$.

\# the significance of differences with the group without signaling molecule inhibitors was noted at $p<0.05$.

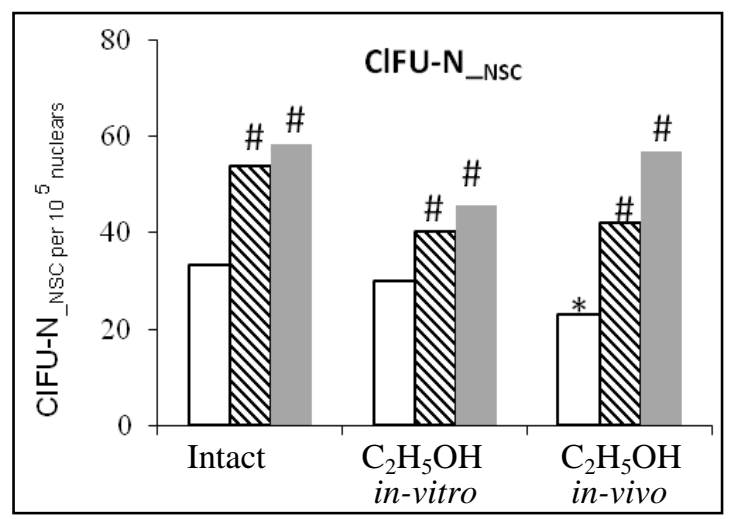

Fig. 1b: Number of ClFU-N_NSC units in the cell culture.

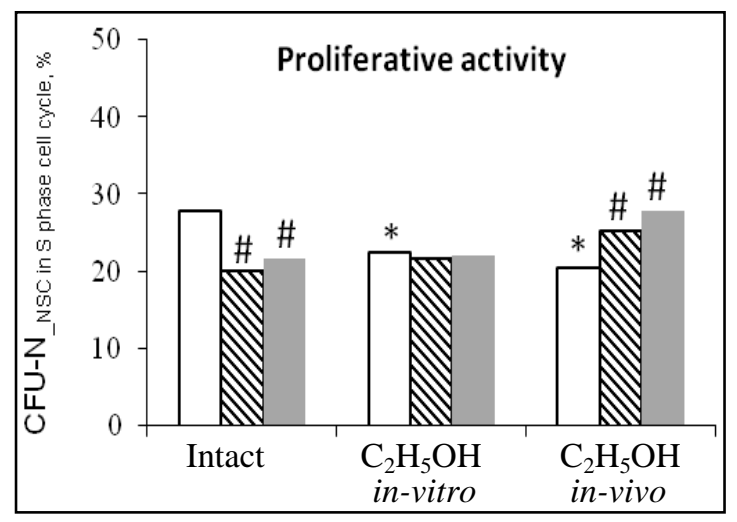

Fig. 1c: Proliferative activity of multipotent neural stem cells.

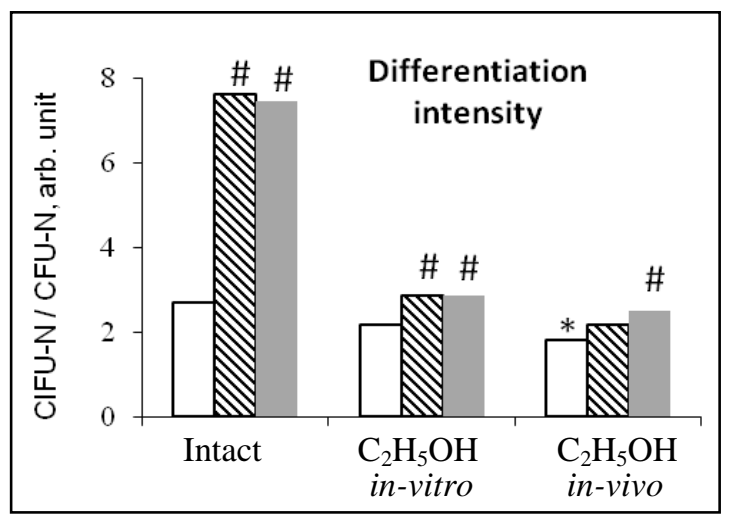

Fig. 1d: Differentiation intensity (CIFU-N / CFU-N) (D) of multipotent neural stem cells.

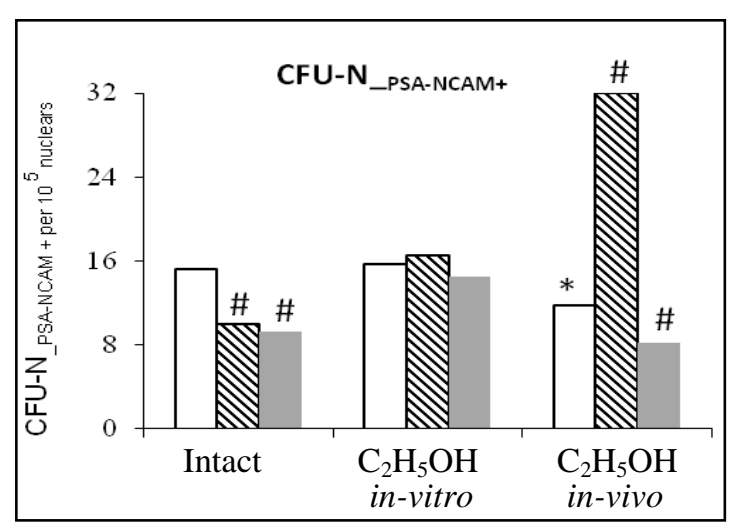

Fig. 2a: Number of CFU-N_PSA-NCAM + in the cell culture.

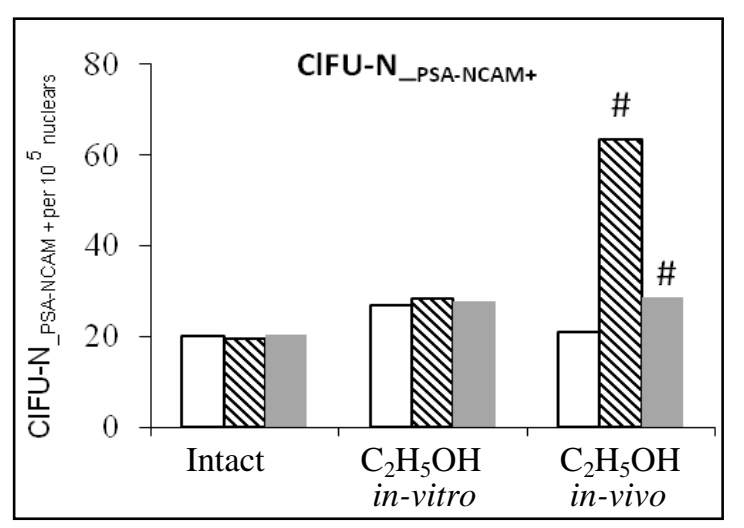

Fig. 2b: Number of ClFU-N_PSA-NCAM+ units in the cell culture. 


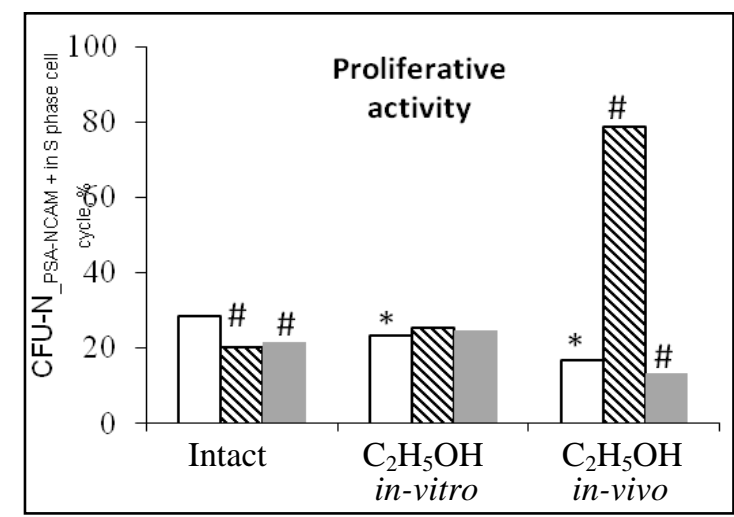

Fig. 2c: Proliferative activity of neuronalcommitted progenitors.

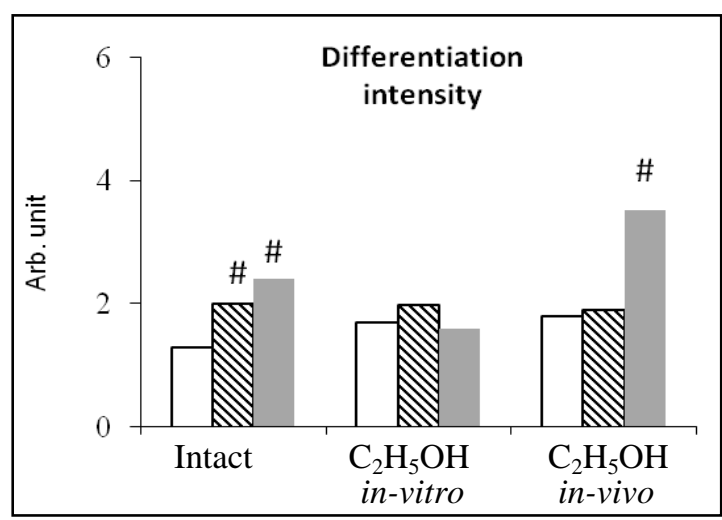

Fig. 2d: Differentiation intensity (CIFU-N_PSA-NCAM+ / CFU-N_PSA-NCAM+) (D) of neuronalcommitted progenitors.

These cells have a limited growth (proliferatedifferentiating) potential compared to CFU. Nevertheless, their in-situ pool is the most mobile ("buffer") section of the cell renewal system, capable of reacting as quickly as possible, and often efficiently, to the effects of damaging factors ${ }^{16 \& 17}$.

\section{Role of ERK1/2 and p38 in implementation functions various types progenitors in ethanol-induced neurodegeneration in-vitro}

Other patterns were revealed during the cultivation of cells of the nervous tissue in the presence of in-vitro ethanol. Inactivation of ERK1/2 and $\mathrm{p} 38$ under these conditions did not affect the colony-forming activity of PSA$\mathrm{NCAM}+$ cells and their proliferativedifferentiation status. However, the blockade of MAPKs affected the functioning of the NSC. Violation of the phosphorylation of ERK1/2 and p38 due to the toxic effects of ethyl alcohol was accompanied by an increase in the yield of ClFU_NSC and the differentiation rate of multipotent precursors (Figs. 1b, 1d). This circumstance indicates the relative functional "stability" of ERK1/2 signaling (at least in the NSC) compared to the p38-dependent mitogenactivated signal transmission.

Role of ERK1/2 and p38 in implementation functions various types progenitors in ethanol-induced neurodegeneration in-vivo

The study of the participation of MAPKs in the functioning of regeneration-competent cells of experimental animals subjected to long-term administration of alcohol revealed even more pronounced changes in their participation in the functioning of progenitor cells. In this case, an inversion of the ERK1/2 and $\mathrm{p} 38$ values was recorded in relation to the mitotic activity of multipotent NSCs: A change in their stimulating role to an inhibitory one. Under the influence of selective blockers ERK $1 / 2$ and p38, an increase in the number of CFU-N_NSC and a progression of their cell cycle was observed in tissue culture (Figs. 1a, 1c). In addition, in-vivo chronic alcoholization of mice led to the appearance of multidirectional ERK1/2 and p38 values in the regulation of CNP functions. Inactivation of ERK1/2 was accompanied by an increase in the intensity of mitoses of CFU-N_PSA-NCAM +, and blockade $\mathrm{p} 38$, on the contrary, to a decrease in this parameter (Fig. 2c). A reflection of the development of these shifts in both cases was the corresponding dynamics of changes in the content of CFU-N_PSA-NCAM + in the culture medium (Fig. 2a). Moreover, the ERK1/2 inhibitor did not affect the maturation rate of neuronal precursors, while impaired signal transmission through MAPK p38 caused a marked increase in their differentiation index (Fig. 2d).

Thus, chronic alcohol intoxication led to significantly different signaling shifts in regeneratively competent cells of the nervous tissue than the action of neurotoxic doses of ethanol in-vitro. Moreover, the formation of the detected "persistent" pattern of intracellular signal transduction (the cellular material for the study was removed 10 days after the end of $\mathrm{C}_{2} \mathrm{H}_{5} \mathrm{OH}$ administration), obviously, was largely due to the multifactorial nature of the pathogenic biochemical "continuum" of the body with long-term alcohol consumption ${ }^{10 \& 17}$. 


\section{Conclusion}

The results of the study confirm the information we obtained earlier ${ }^{8 \& 16}$ about the significant specificity of the participation of individual links of MAPK pathways in the regulation of the functions of progenitor cells of various classes. In this case, for the first time, fundamental differences were found in the p38 value in the regulation of the cell cycle of multipotent NSCs and committed neuronal precursors $^{17}$ in ethanol-induced neurodegeneration. This circumstance casts doubt on the prospects of developing targeted pharmacological approaches to the treatment of alcohol encephalopathy by acting on the links of the "alternative" (p38-dependent) MAPK signaling ${ }^{8 \& 18}$. At the same time, the revealed phenomena testify in favor of the possibility of stimulating neurogenesis of the alcoholaffected central nervous system due to the synchronized increase in the realization of the growth potential of the parent elements of both types using ERK1/2 activity modifiers. However, the difference in the vector of the role of ERK1/2 in progenitor cells under optimal life conditions and in ethanol-induced neurodegeneration does not allow us to draw unambiguous conclusions about the effectiveness of their use. There is a risk of an undesirable effect on the functioning of regeneration-competent cells in the event of a sanogenetic transformation ${ }^{19}$ of the "perverted" alcohol-associated pattern of ERK1/2dependent signaling that is naturally expected in them during therapy. Thus, the use of the ERK1/2 inhibitor in the pronounced clinical manifestation of ethanol-induced neurodegeneration and the cancellation of its use when there are signs of reconvalescence seems promising.

\section{REFERENCES}

1- G. N. Zyuz kov, V. V. Zhdanov, E. V. Udut, L. A. Miroshnichenko, T. Yu. Polyakova, L. A. Stavrova and V. V. Udut, "Strategy of pharmacological regulation of intracellular signal transduction in regeneration-competent cells", Bull. Exp. Biol. Med., 166, 448-455 (2019).

2- G. N. Zyuz'kov, N. I. Suslov, L. A. Miroshnichenko, E. V. Simanina, T. Yu. Polyakova, L. A. Stavrova, V. V.
Zhdanov, M. Yu. Minakova, E. V. Udut and V. V. Udut, "Halogenated (Cl-ion) songorine is a new original agonist of fibroblast growth factor receptors of neuronal-committed progenitors possessing neuroregenerative effect after cerebral ischemia and hypoxia in experimental animals", Biointerface Res. Appl. Chem., 9, 4317-4326 (2019).

3- G. N. Zyuz'kov, L. A. Miroshnichenko, T. Yu. Polyakova, L. A. Stavrova, E. V. Simanina and V. V. Zhdanov, "Specific roles of JAKs and STAT3 in functions of neural stem cells and committed neuronal progenitors during ethanol-induced neurodegeneration", Bull. Exp. Biol. Med., 168, 356-360 (2020).

4- G. N. Zyuz'kov, V. V. Zhdanov, E. V. Udut, L. A. Miroshnichenko, E. V. Simanina, T. Y. Polyakova, L. A. Stavrova, V. V. Udut, M. Y. Minakova and A. M. Dygai, "Involvement of JAK1, JAK2, and JAK3 in stimulation of functional activity of mesenchymal progenitor cells by fibroblast growth factor", ibid., 162, 240-243 (2016).

5- A. H. Koeppen, "The neuropathology of the adult cerebellum", Handb. Clin. Neurol., 154, 129-149 (2018)

6- K. Zhang, H. Wang, M. Xu, J. A. Frank and J. Luo, "Role of MCP-1 and CCR2 in ethanol-induced neuroinflammation and neurodegeneration in the developing brain", J. Neuroinflammation, 15, 197 (2018).

7- L. G. Jr. Coleman, J. He, J. Lee, M. Styner and F. T. Crews, "Adolescent binge drinking alters adult brain neurotransmitter gene expression, behavior, brain regional volumes, and neurochemistry in mice", Alcohol Clin. Exp. Res., 35, 671-688 (2011).

8- G. N. Zyuz'kov, V. V. Zhdanov, L. A. Miroshnichenko, E. V. Udut, A. V. Chaikovskii, E. V. Simanina, M. G. Danilets, M. Yu. Minakova, V. V. Udut, T. G. Tolstikova, E. E. Shults, L. A. Stavrova, Ya. V. Burmina and A. M. Dygai, "Involvement of PI3K, MAPK ERK1/2 and p38 in functional stimulation of mesenchymal progenitor cells by alkaloid songorine", Bull. Exp. Biol. Med., 159, 58-61 (2015). 
9- K. Nixon, "Alcohol and adult neurogenesis: Roles in neurodegeneration and recovery in chronic alcoholism". Hippocampus, 16, 287-295 (2006).

10- M. Tateno and T. Saito, "Biological studies on alcohol-induced neuronal damage", Psychiatry Investig., 5, 21-27 (2008).

11- J. C. Brust, "Acute withdrawal: Diagnosis and treatment", Handb. Clin. Neurol., 125, 123-31 (2014).

12- G. P. Jordaan and R. Emsley, "Alcoholinduced psychotic disorder: A review", Metab. Brain Dis., 29, 231-43 (2014).

13- G. N. Zyuz'kov, L. A. Miroshnichenko, E. V. Udut, A. V. Chaikovskii, T. Yu. Polyakova, E. V. Simanina, L. A. Stavrova, V. I. Agafonov and V. V. Zhdanov, "Functional state of various types of regeneration-competent cells in the nervous tissue in ethanol-induced neurodegeneration", Bull. Exp. Biol. Med., 166, 317-320 (2019).

14- T. Seki, "Expression patterns of immature neuronal markers PSA-NCAM, CRMP-4 and NeuroD in the hippocampus of young adult and aged rodents", J. Neurosci. Res., 70, 327-334 (2002).
15- M. J. Curtis, R. A. Bond, D. Spina, A. Ahluwalia, S. P. Alexander and M. A. Giembycz, "Experimental design and analysis and theirreporting: New guidance for publication in BJP", $\boldsymbol{B r} . \boldsymbol{J}$. Pharmacol., 172, 3461-3471 (2015).

16- G. N. Zyuz'kov, V. V. Zhdanov, E. V. Udut, L. A. Miroshnichenko, T. Yu. Polyakova, L. A. Stavrova, A. V. Chaikovskii, E. V. Simanina, M. Y. Minakova and V. V. Udut, "Peculiarities of intracellular signal transduction in the regulation of functions of mesenchymal, neural, and hematopoietic progenitor cells", Bull. Exp. Biol. Med., 167, $201-$ 206 (2019).

17- K. Nixon, "Alcohol and adult neurogenesis: Roles in neurodegeneration and recovery in chronic alcoholism", Hippocampus, 16, 287-295 (2006).

18- M. Mavers, E. M. Ruderman and H. Perlman, "Intracellular signal pathways: Potential for therapies", Curr. Rheumatol. Rep., 11, 378-385 (2009).

19- N. Takeuchi and S. Izumi, "Maladaptive plasticity for motor recovery after stroke: Mechanisms and approaches", Neural. Plast., 2012, 359728 (2012). 


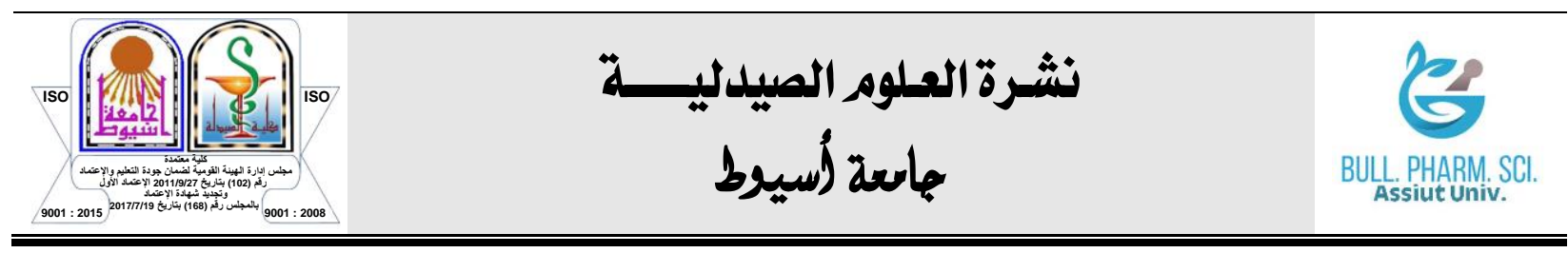

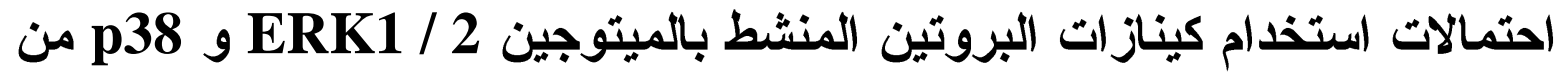
أسلاف الأسجة العصبية كأهداف دوائية لعلاج التنكس العصبي التئين التاجم عن الكحول جليب ن. زيوزكوف - لاريسا أ.ميروشنيشنكو - إيلينا ف.سيمانينا - تاتيانا يو . بولياكوفا معهد جولدبيرج لبحوث الصيدلة والطب التجديدي ، مركز تومسك الوطني للبحوث الطبية ، الأكاديمية

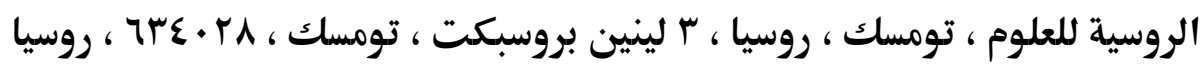

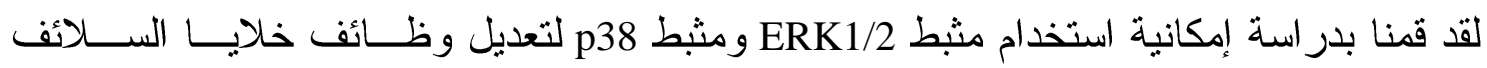

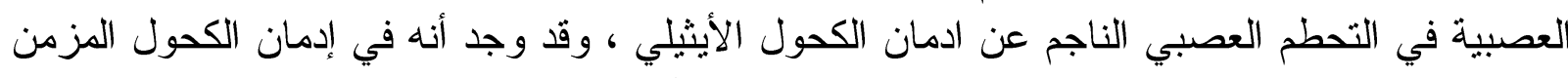

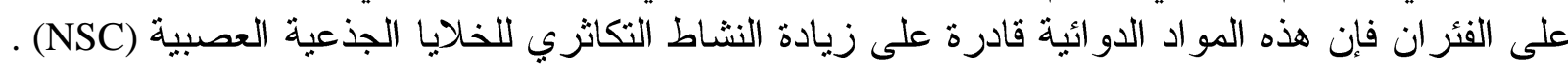

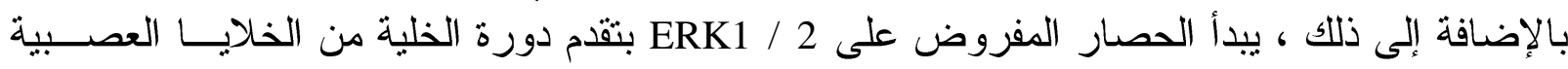

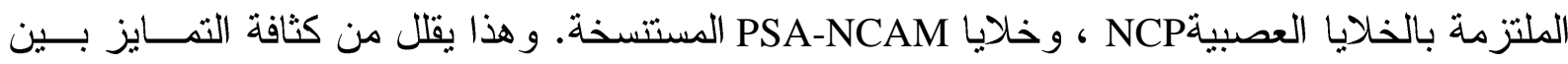

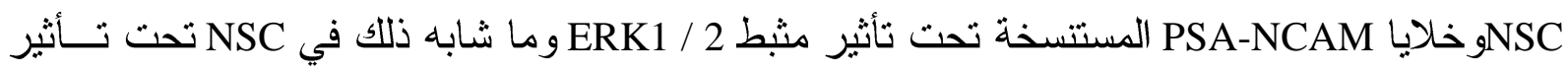

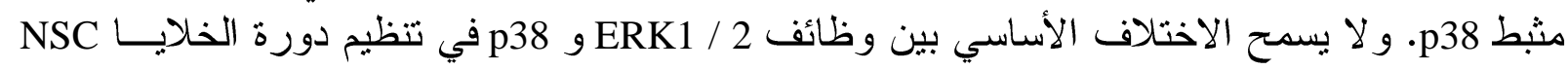

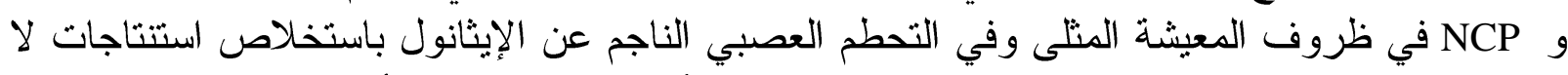

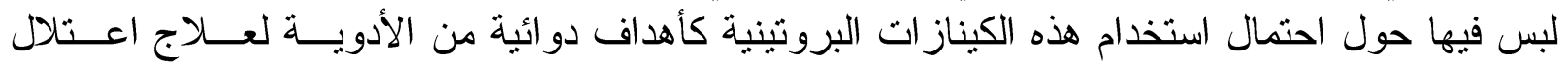
الدماغ الكحولي. 